\title{
Confluências externas e internas
}

Refletir sobre a formação do professor é considerar sua inserçāo num contexto social dinâmico, numa pluralidade de tempos e espaços que não respeitam o espaço geométrico. A escola é apresentada sob suas múltiplas configuraçōes, como um corpo vivo pulsando. A formação do professor é pensada como um processo virtual que se atualiza na medida em que ocorre, coerentemente com o lugar e tempo, atenta às mudanças nos diversos âmbitos da sociedade, apropriando-se delas.

\section{Vitória Kachar Hernandes}

Doutoranda no Programa de Pós-Graduação em Educação: Currículo da PUC/SP. Vice-coordenadora do sub-projeto de Informática na Educação do Programa de Educação Continuada da Secretaria de Estado da Educação de São Paulo. Consultora e docente na área de Educacão e Informática.

Antes de refletir sobre a formação do professor que é nossa finalidade, passaremos por algumas reflexões anteriores. Pensar que sociedade, qual está se fazendo e que está para se fazer, auxiliando a dimensionar o contexto. Da mesma forma, observar de fora qual escola estamos nos deparando e dirigindo nossa ação educacional. E entrar no mundo subjetivo do indivíduo para conhecer como reage às influências e conflitos gerados por esse meio. Considerando esses âmbitos e a rede de imbricamentos entre eles e interferências, questionar e tentar dimensionar $o$ processo de formação do professor na era atual.

\section{A Sociedade e sua velocidade}

Vivemos um momento caracterizado pela velocidade das mudancas. Mal conseguimos acomodar uma transformação, já surge outra gerando a desestabilização.

"Certamente nunca antes as mudancas das técnicas, da economia e dos costumes foram tão rápidas e desestabilizantes".(Lévy, 1996:11)

A sociedade de hoje em oposição a um estado estático e estável mostra-se densa, complexa em movimento e mutação, transparecendo suas modificaçōes em todos os setores da vida do indivíduo, marginalizando, pressionando aqueles que não acompanham o movimento. A crescente invasão tecnológica no campo cultural, econômico, social e científico, colabora intensivamente na geração de uma profusão de universos que se misturam, se mesclam em múltiplas variaçōes.

Os espacos se metamorfoseiam e se bifurcam a nossos pés, forcando-nos à hete- rogênese. (Léw, 1996: 23)

Uma pluralidade de tempos e espaços que não respeitam o espaço geográfico e o tempo cronológico surgem questionando a uniformidade e a fixidez. O sistema de transporte e de comunicação aproxima e conecta os indivíduos, modificando o estado anterior das coisas, num processo dinâmico de aceleração da comunicação e da mobilidade física.

Cortelazzo afirma que iniciamos nossa entrada na sociedade da comunicação, sugerindo que saímos da sociedade industrial e estamos na da informaçāo ${ }^{2}$. (in org. Bicudo e Júnior, 1996)

Os limites e fronteiras entre os territórios se tornam flexíveis e permeáveis, propiciando a passagem do interior para o exterior e vice-versa. Por exemplo: as relaçōes entre o privado e o público, objetivo e 0 subjetivo. (Léwy, 1996). Ou, se pensarmos no trabalhador clássico de antes, tinha seu espaço físico delimitado dentro da empresa, em comparação com o empregado de hoje (e futuro), que pode desempenhar muitas das atividades na sua própria casa. A evolução das técnicas torna possível o estar aqui e lá ao mesmo tempo. Os equipamentos médicos tornam aparente e visível o interior do nosso corpo e criam próteses misturando corpo com artefato.

A técnica produzida pelas ciências transforma a sociedade (Morin, 1990: 16) e, por seu lado, a sociedade tecnologizada modifica a ciência e, assim, se mantém um ciclo contínuo e cada vez mais complexo e acelerado. A sociedade de hoje está distante da de ontem e estará distante da de amanhã.

Antes se trabalhava com a dimensão do passado no presente, agora trabalha-se
2 Ela embasa seu discurso no trabalho e pesquisa que desenvolve com redes eletrônicas com professores. 
com a dimensão do futuro, com o prognóstico. Algumas empresas planejam e produzem produtos que provavelmente serão consumidos pelos que virão depois ou para situaçōes que ainda não existem, chegando a contratar futurólogos para essa funçāo.

Então, a sociedade transformada e transformadora, projetada para um devir, concebe instituiçōes e individuos que refletem esse modo de ser.

\section{A Escola e a possibilidade de múltiplas configuraçōes}

Ao olharmos a escola de hoje, nos deparamos ainda com um forte traço de sua origem se configurando na condição da estabilidade, conservação e reprodução. No seu surgimento, na sociedade grega, a escola significava um lugar coletivo para manter a unidade e a estabilidade, em oposição à diversidade de costumes que emergiam nas famílias e às ameaças dos bárbaros. (Espósito, in Serbino e Grande, 1995)

Sistematicamente, isto é, organizada como um corpo de doutrinas, leis e principios, a escola teria a finalidade de ordenar uma série de fenômenos, modos de vida, hábitos. Nasce, pois, a escola num tempo de sociedade. Uma sociedade que, para ser, solicita a escola. (Espósito, in Serbino e Grande, 1995: 116)

A escola apresentou-se na sua origem como um local para a manutenção de uma disciplina e ordem, nascidas da necessidade da sociedade sobreviver, evitar o seu esfacelamento e promover sua integridade.

Bryan sustenta a congruência que existe entre sistema de ensino e estrutura social, que não é obra do acaso (in org. Bicudo e Júnior, 1996). Mas não é sempre assim que a escola se mostra.

Dewey, no seu tempo, questionou a escola apontando a reprodução dos mesmos métodos e conteúdos no passar dos anos, como se o que tivesse sido bom para uma geração seria para outra, a seguinte.

O que se espera da escola é que ela seja contemporânea da sociedade; Freire enfatizou isso. Parece até que ela acompanha o cenário social e político da sua época, até por uma questão da sua sobrevivência, mas às vezes, sofre o descompasso. Nāo vemos com simplicidade a incorporação do ritmo das mudanças da sociedade pela es- cola, e nem acreditamos que ela deixe de ser o que é para tornar-se outra. Nela subsistem o velho e o novo, o estático e o dinâmico.

A escola pode ser lida na sua complexidade e diversidade, não descartando a existência das várias faces. Uma multiplicidade de formas que historicamente foram se constituindo no tempo através do ser e fazer educacional.

Vamos observar a escola pelas influências sofridas pelas germinaçōes da tecnologia no seu meio, que a impelem a novas formas e configuraçōes.

Uma nova configuração da escola decorre da possibilidade dela se estender para outros locais virtuais, apresentando outros lugares e momentos para a ocorrência da aprendizagem, explorando a informaçāo e o conhecimento. Outros espaços possíveis estão se tornando presentes no cotidiano da vida escolar e do indivíduo.

Encontramos informação e formação através das tecnologias de comunicaçāo: televisāo (tv a cabo), vídeo, computador (em casa), videogame, etc, onde o indivíduo gasta grande parte do tempo envolvido numa interaçāo passiva ou ativa, dependendo do veículo de mediação, intervindo na recepção das informações veiculadas.

A Internet é um exemplo de mídia eletrônica de comunicação que tem-se apresentado como um braço da escola, potencializando-a e, ao mesmo tempo, despotencializando-a.

A escola pode ser observada como um corpo vivoao dimensionar o processo de centralização e descentralização que acontece por efeito da inovação tecnológica no seu ambiente. Ela pode ser considerada como um centro de agregação do coletivo humano para a sistematização do conhecimento, através da convergência de açōes estruturadas de educação. E através de um movimento para dentro de recepção, por meio de outros canais de ação educacional ligados com o mundo, se alimenta de mais potência com os novos recursos para a exploração e produção do conhecimento. Em oposição a essa direção um movimento para fora a leva para as extremidades, fragmentando-a e espalhandoa em partes e disseminando sua função para outros locais, como ramificaçōes. Neste processo de ir para os seus extremos e vir para o centro, a escola pode apresentar-se como um 
corpo vivo pulsando, oxigenando-se com o contato gerado fora do seu meio.

As infovias caracterizam-se como um veículo de acesso democrático a qualquer tipo de informação. Toda diversidade de conhecimentos de vários lugares do mundo podem ser buscados pela escola fora dela, fazendo ponte e conversando com pessoas, empresas, outras escolas enfim, com a sociedade, sofrendo as interferências advindas do rompimento dos muros.

As informações e os conhecimentos apresentam-se em diversos formatos, fotos, textos, animaçōes, etc., o que enriquece as possibilidades de um aprender mais interativo e com o jeito da sociedade e do indivíduo de hoje. Mas o aprendiz e o professor precisam estar preparados para ter condiçōes favoráveis de domínio operacional e educacional, para aproveitar a navegaçāo na via da informação, definindo o objeto da sua busca, assim como, sabendo onde procurar, como selecionar e analisar se a informação é consistente e coerente, pois nāo há ainda um tipo adequado de filtro do que é veiculado por esse meio. Há uma certa banalização do conhecimento, clássicos e histórias mal elaboradas convivem no mesmo ambiente na mesma prateleira. Do usuário exige-se um olhar mais atento e crítico para não estar consumindo leitura vulgar por científica.

Questiona-se a competência da escola como informadora, e espera-se dela a preparação do indivíduo para lidar com esse mundo que se desvela de várias formas. Os conteúdos e métodos são colocados em questionamento com relação a sua adequaçāo aos tempos atuais.

Com as mídias eletrônicas não há um tempo para começar e um para acabar; pressupōe um aprender que não se restringe a um mínimo e máximo de idade, e nem a um limite de número de indivíduos. Elas viabilizam 0 acesso à quantidade intensificando o tempo. $O$ poder de atingir muitos é útil $\mathrm{e}$ democratizante, porém pode provocar prejuizo ao nível da qualidade educacional.

A dimensão de tempo e espaço é relativizada, podendo-se estar aqui e lá ao mesmo tempo, ver a Mona Lisa no museu de Louvre sem ter que abandonar as atividades profissionais ou escolares. Ganha-se com o tempo e com o espaço na possibilidade de locomoção virtual para se comunicar com o outro ou estar em outros lugares antes ina- cessiveis.

O mundo invade a escola e ela entra no mundo. A escola fica inflada e exposta ao público. Estas possibilidades de estar em contato direto com outros lugares e outros espaços permitem a intensificação da interferência social e cultural, produzindo releituras e a sua oxigenação. Intercâmbios com o outro ampliam o contato com o exterior, com o diferente e com o desconhecido, modificando ambos.

A abertura para a diversidade se apresentar sem preconceitos, incômodos, valorizando na sua capacidade de gerar cidadãos mais críticos e conscientes.

A comunicaçáo via re de de computadores entre alunos de regiōes e culturas diferentes permite-/hes perceber que o mundo é maior e mais diversificado do aquele em que eles vivem. Nāo só lhes permite aprender sobre outros modos de viver, outras histórias, outros modos de pensar, mas também a contrapor a sua própria cultura, começar a conhecê-la, uma vez que eles vão ser estimulados a falar sobre ela, e a se orgulhar ou não de suas tradiçōes, criandose assim um embasamento sólido para o crescimento de cidadãos críticos, conscientes, atuantes e modificadores da sociedade. (Cortelazzo, in org. Bicudo e Júnior, 1996: 90)

Aprende-se a navegar sem fronteiras, uma metáfora para o pensamento que não encontra limites para viajar em outros territórios e divagar em outras circunstâncias.

As ramificações da escola a configuram de um outro jeito, de vários jeitos. $O$ processo ordenado e disciplinar instituído à escola no seu início, abre-se para um outro, indisciplinar e caótico, gerando uma abertura para sua renovação e contextualização na sociedade e na vida. Uma reconstrução considerando o contexto temporal, espacial e social.

Mais que isto, interrogar a escola na sociedade e no tempo implica vêla no imbricamento do tempo e do espaco, no movimento perene, na construção e na "desconstrução" ... para "re-construir". Isto significa resgatar no tempo, na escola e na sociedade o homem que al está sendo. Slgnifica reconhecer a diversidade desse estar no mundo e, quem sabe, conseguir captar na fragrância da sua fluidez, nos rastros do seu fazer-se, a unidade dessa diversidade. (Espósito, 1995: 120) 


\section{$\mathbf{O}$ individuo e a subjetlvidade}

O mundo pode ser lido e vivido de diversos modos e cada qual tem sua riqueza no universo criado que lhe é peculiar e singular. Cada pessoa tem sua identidade apresentando-a como essência de seu modo de ser, agir, pensar, sonhar, etc.

Nos dias atuais há uma sensibilização do global e uma supressão do que é secreto e, talvez, o perigo do desenrolar de uma perda de identidade cultural (Ramos, 1997).

Vamos fazer uma releitura das colocaçōes de Rolnik (1997) em relação a subjetividade em tempos de globalização, onde gera-se o que ela chama de "toxicômanos de identidade". Nesses tempos há uma intensificaçāo de contatos entre os universos de qualquer ponto do mundo provocando uma troca infindável como surgimento de um coletivo anônimo, influenciando na configuraçāo da subjetividade.

Assubjetividades, independentemente de sua morada, tendem a ser povoadas por afetos dessa profusão cambiante de universos; uma constante mesticagem de forcas delineia cartografias mutáveis e coloca em cheque seus habituais contornos. (Rolnik, org. lins, 1997: 19)

A intervenção na subjetividade apresenta-se como processo de desestabilizaçāo, desenrolando-se através da interação do indivíduo com a rede complexa de universos em que se insere. A ameaça vinda por esse turbilhão de micro e macro universos invasores da privacidade, fazem a subjetividade sofrer as tensōes do fora com o dentro do individuo, desenhando outras figuras da subjetividade em cada momento. As misturas geram uma intensificação da pulverização da identidade e, por outro lado, a globalização cria modelos que são disseminados para serem consumidos no mercado. As novelas de televisão ou as novelas construídas em cima do drama da vida real divulgadas pela mídia dos jornais, das revistas, vêm recheadas de modelos, valores, éticas e estéticas. Elas podem ser consideradas como exemplos de modelos. $O$ indivíduo é atingido continuamente por estímulos novos que o induzem a mudar seu comportamento.

Identidades locais fixas desaparecem para dar lugar a identidades globalizadas flexíveis, que mudam ao sabor dos movimentos do mercado e com igual velocidade. (RoInik, 1997: 20)

Assim, surge um conflito no indivíduo entre 0 alienar-se e manter-se a margem do que acontece, mantendo a fixação de sua referência identitária ou então a desestabilizaçāo exagerada produzida pelas numerosas forças de fora.

O indivíduo sente-se ameaçado ao embrenhar-se no processo de mover-se ao sabor dos acontecimentos e mudanças, gerando um caos psíquico dificilmente suportado pelo indivíduo.

Tanto a situacāo de fixidez de identidade como a tentativa de sua globalização fracassam na manutenção de uma subjetividade saudável.

$O$ fruir da riqueza da atualidade depende de as subjetividades enfrentarem os vazios de sentido provocados pelas dissolucões das figuras $\mathrm{em}$ que se reconhecem a cada momento. Só assim poderão investir a rica densidade de universos que as povoam, de modo a pensar o impensável e inventar possibilidades de vida. (Rolnik, 1997: 24)

Uma ação voluntária e consciente do indivíduo dependerá da reflexão que fará sobre si, sobre os outros universos e as relações que estabelece com estes, aprendendo a lidar com a avalanche pelo qual se sente ameaçado, sempre atento às forças internas e externas que se mobilizam no conflito, criando formas de viver a multiplicidade de universos que emergem da sociedade.

\section{A Formação do Professor diante das con- fluências externas e internas}

O pensar sobre o professor e a sua formação necessita considerar todo o volume de modificaçōes que se transfiguram na sociedade e como ele pode apropriar-se delas sem perder sua identidade enquanto educador.

Refletir sobre a formação do professor na efervescência atual e o no que está apontando para ser. Tomar o presente e, também, projetar-se para um futuro próximo, assim como, dar-se conta dałdimensão espacial que ultrapassa os limites das paredes da escola, considerando a dinâmica de relaçōes entre espaço e tempo, conectada com a sociedade, escola e individuo que estão sendo e 
que estão para ser.

A formação pode ser expressa como um processo virtual que se atualiza na medida em que ocorre, coerentemente com o lugar e tempo, atenta às mudanças nos diversos âmbitos da sociedade, apropriandose delas. Colocando a formação em constante reformulação e construção, gestadas no conflito entre o velho e o novo, o instituído e o instituinte.

A concepção de formação de professor não fica delimitada pelo espaço físico da escola, mas sim conquistando outros locais de ação direta, como os veiculados pelas tecnologias e mídias eletrônicas, implicando no domínio destes recursos possíveis de uso na ação educativa, analisando essas ferramentas e seus usos, para intervir através de uma reflexão teórica e prática da sua adequação e riqueza para o processo de formação educacional.

Levar o professor a depurar sua leitura e seu olharno reconhecimento dos modelos de aprendizagens subjacentes à sua prática e a de outrem, assim como, nos recursos tecnológicos em uso. Na exploração dos computadores como recursos de aprendizagem, observar nos softwares as concepções pedagógicas que carregam. Ao perceber e reconhecer, ele pode refazer e reconstruir em uma nova abordagem, inventando outros ambientes de aprendizagem atualizados com as modificações sociais e culturais.

A formação do professor deve abarcar as novas ferramentas e os novos locais que emergem como possíveis de exploração do conhecimento e na nova configuração de escola. Isso implica numa preparação do indivíduo com e para os recursos tecnológicos disponíveis, não só o instrumentalizando, mas fazendo com que se aproprie do processo de utilização: o pensarsobre o recurso e o pensar sobre o fazer com ele, explorando o melhor que cada um pode oferecer e criando ambientes propicios para o aprender. Mas isso não é possível quando a imersāo do indivíduo é só no fora de si, mas quando também abarca o dentro de si.

Dar-se conta dos conflitos e intensidades que permeiam seu pensamento e seu agir, que influenciam a sua açāo pedagógica. Conhecer seus próprios limites e encontrar o passo equivalente a sua possibilidade de caminhar na direção da sua transformação e a que pode propiciar ao outro. Viabilizar, através da reflexāo teórica, um melhor entendimento e depuração da própria prática, para que o educador possa ressignificála e reconstruí-la, implicando num aprofundamento que possibilite a tomada de consciência do seu pensare agir na educaçāo. Apropriar-se da sua ação de uma maneira mais integrada, navegando no seu mundo interior para descobrir melhor o exterior. A elaboração de um conhecimento externo pressupōe um conhecimento interno.

Enão se trata apenas de conhecimento, mas também de compreensão, acordo entre os próprios meios e fins e pulsões, 0 que implica possibilidade de exercitar um certo domínio sobre as próprias inclinacōes $e$ açōes, a fim de que elas nos controlem $e$ dirijam mas nāo nos coíbam ou sufoquem. (Calvino, 1994: 106)

O educador precisa saber lidar com as diferenças que existem no outro, observando-os fora de si, e também dar-se conta do diverso que existe e pode coexistir em si, não necessariamente excludentes, dando espaço para que o diverso no pensare no ser transborde, escapando do comportamento linear e esperado, vivendo come a partir do diferente que existe no seu próprio ser. $O$ adormecido pode aflorar e o indivíduo se experimentar diferente diante de um mesmo objeto ou de uma mesma situação, propiciando a mudança. Assim, possibilita-se uma verdadeira transformação que deixa de ser só discurso para ser também ação. A mudança efetiva na formaçāo do professor implica em vivenciar o diferente no outro e em si próprio e refletir sobre eles, gerando modificações no meio educacional.

A formação precisa considerar a necessidade de preparar um indivíduo que saiba lidar com a instabilidade, pois não é viável usar a mesma prática para as novas situaçōes. O lidar com o novo, diferente e o movimento, exige uma ação reflexiva que questiona o estabelecido, reformula o problema, construindo e testando novas abordagens (Wolcott, 1995). Essa reflexão não acontece só e nem se esgota na formação, mas se estende na prática profissional como uma necessidade contínua de alimentação com o conhecimento, não se fazendo na solidāo, mas na parceria e troca com teóri- 


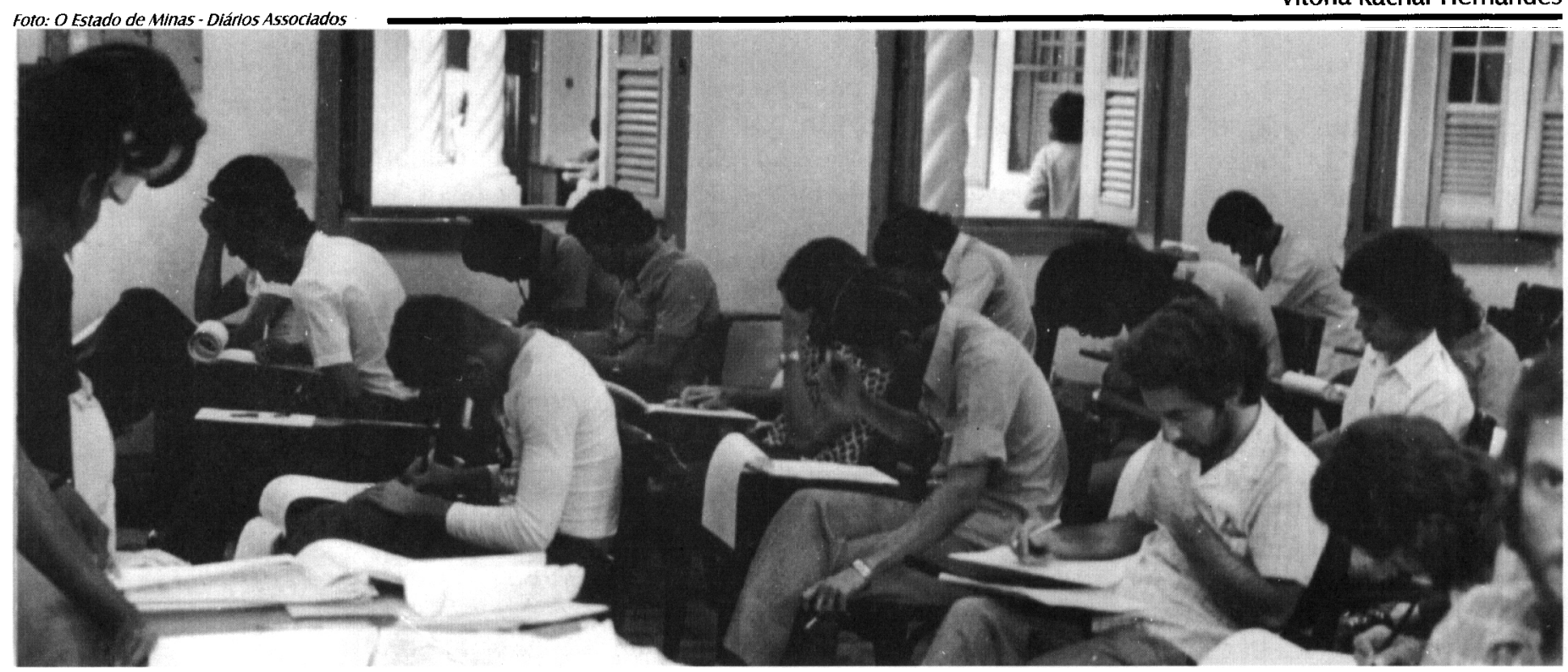

cos, colegas e alunos. Desenvolver a reflexão da (sobrie) ação e na (durante) ação, em outras palavras, um olhar analítico sobre a ação, antes (na perspectiva do que poderá ser), durante e depois.

Gallo acredita na "Filosofia da Educação" como um "instrumental reflexivo" para o professor se armar de condições e auxiliá-lo a refletir sua prática pedagógica, sem a qual ficaria empobrecida e desqualificada. (1996)

Observar as dificuldades que o professor enfrenta, instigando-o a olhar para dentro de si para não se deixar levar pela pressāo de fora ou aceitando a imposição de um modismo, sabendo refletir e agir em cada momento de acordo com sua singula- ridade.

Neste caso, globalizar não significa pulverizar e nem homogeneizar, mas aproximar o contato com as diferenças para que delas possam surgir novas diversidades que atendam às necessidades e singularidades do indivíduo. Sem negar a realidade e enclausurar-se num mundo a parte, como resistência às mudanças e transformações, e nem submetendo-se totalmente a elas.

Mais que formação e menos que conformação, criar um espaço de discussão e investigação das questōes educacionais experimentadas na prática, abrindo um canal de diálogo com as dificuldades de ser professor num contexto social em veloz transformação.

\section{Referências Bibliográficas}

Bryan, N.A.P. (1996). Desafios educacionais da presente mutaçāo tecnolóoica e oroanizacional para a formacāo de professores do ensino tecnológico. Formacāo do Educador. (org. BICUDO e JÚNIOR). UNESP, volume 3.

Calvino, I. (1994). Palomar. (trad. Ivo Barroso). Companhla das Letras.

Cortelazzo, I.B.C. (1996). Utilização pedagógica das redes eletrônicas. Formação do Educador. (org. BICUDO and JÚNIOR). UNESP, volume 3.

Espósito, V.H.C. (1995). O que é isto, a escola? (org. SERBINO and GRANDE) $A$ escola e seus Alunos. UNESP, São Paulo.

Gallo, S. (1996). A filosofia e a formação do educador: os desafios da modernidade. Formação do Educador. (org. BICUDO and JÚNIOR). UNESP, volume 2.
Lévy, P. (1996). O que é virtual? Sāo Paulo: Editora 34.

Morin, E. (1990). Ciência com Consciência. Portugal: Publicaçōes Europa-América.

Ramos, R.Y. (1997). Hacia Una Educación Global desde la Transversalidad. Spain: Anaya.

Rolnik, S. (1997). Toxicômanos de Identidade - subjetividade em tempo de globalização, in LINS, D. (oro.). Cultura e Subjetividade - saberes nômades. São Paulo: Papirus.

Rolnik, S. (1997a). Uma insólita viagem à subjetividade fronteiras com a ética e a cultura, in LINS, Daniel (org.). Cultura e Subjetividade - saberes nômades. São Paulo: Papirus.

Wolcott, L.L. (1995). The distance teacher as reflective practitioner, Educational Technology, jan-fev, 39-43. 